\title{
Comparison of Helminth Infection among the Native Populations of the Arctic and Subarctic Areas in Western Siberia Throughout History: Parasitological Researches on Contemporary and the Archaeological Resources
}

\author{
Sergey Mikhailovich Slepchenko, ${ }^{1, * *}$, Sergey Vladimirovich Bugmyrin³, Andrew Igorevich Kozlov, \\ Galina Grigorievna Vershubskaya ${ }^{4}$, Dong Hoon Shin ${ }^{5}$ \\ ${ }^{1}$ Tyumen Scientific Center, Siberian Branch of the Russian Academy of Sciences, 86 Malygina Street, Tyumen, 625003, Russian Federation; \\ ${ }^{2}$ Surgut State University, 1 Lenin Avenue, Surgut, 628408, Russian Federation; ${ }^{3}$ Institute of Biology, Karelian Research Centre, Russian Academy of \\ Sciences, 11 Pushkinskaya St, Petrozavodsk, 185910, Russian Federation; ' Anuchin Research Institute and Museum of Anthropology, Lomonosov \\ Moscow State University, 11 Mokhovaya street, Moscow, 119992, Russian Federation; ${ }^{5}$ Laboratory of Bioanthropology, Paleopathology and History \\ of Diseases, Institute of Forensic Science/Department of Anatomy, Seoul National University College of Medicine, Seoul 03080, Korea
}

\begin{abstract}
The aim of this parasitological study is examining contemporary (the late 20th century) specimens of the arctic or subarctic areas in Western Siberia and comparing them with the information acquired from archaeological samples from the same area. In the contemporary specimens, we observed the parasite eggs of 3 different species: Opisthochis felineus, Ascaris lumbricoides, and Enterobius vermicularis. Meanwhile, in archaeoparasitological results of Vesakoyakha, Kikki-Akki, and Nyamboyto I burial grounds, the eggs of Diphyllobothrium and Taenia spp. were found while no nematode (soil-transmitted) eggs were observed in the same samples. In this study, we concluded helminth infection pattern among the arctic and subarctic peoples of Western Siberia throughout history as follows: the raw fish-eating tradition did not undergo radical change in the area at least since the 18th century; and A. lumbricoides or $E$. vermicularis did not infect the inhabitants of this area before 20th century. With respect to the Western Siberia, we caught glimpse of the parasite infection pattern prevalent therein via investigations on contemporary and archaeoparasitological specimens.
\end{abstract}

Key words: Contemporary, archaeoparasitology, burial ground, Western Siberia

The application of parasitological technique to the archaeological remains makes us understand the parasite infection pattern more relevant with spatio-temporal aspects $[1,2]$. Many researchers reported certain types of parasites in archaeological specimens, subsequently reconstructing the parasite infection, diet, human migration, and other factors somehow relating to a mankind history $[3,4]$. This is also true for the arctic or subarctic territory of Western Siberia, where different ethnic populations have lived in the nomadic and semi-nomadic ways [5]. However, as for the historical changes of parasite infection in arctic or subarctic areas, the pattern is not evidently revealed so far because the reported cases from the re-

- Received 31 July 2019, revised 6 September 2019, accepted 13 September 2019.

*Corresponding author (s_slepchenko@list.ru)

(c) 2019, Korean Society for Parasitology and Tropical Medicine

This is an Open Access article distributed under the terms of the Creative Commons Attribution Non-Commercial License (http://creativecommons.org/licenses/by-nc/4.0) which permits unrestricted non-commercial use, distribution, and reproduction in any

medium, provided the original work is properly cited. gion are not sufficient yet. This study is thus aimed to examine contemporary (the late 20th century) specimens of the arctic or subarctic areas in Western Siberia, then comparing them with the information acquired from archaeoparasitological studies on the same area. We finally estimate intergroup difference between contemporary and archaeoparasitological resources, and deduce conditional factors relating with it.

As for contemporary data, we used our copro-ovoscopic population survey data in 1988-1989. The analysis was conducted on the ethnical settlements at the Berezovskii District of the Khanty-Mansi Autonomous Okrug. Data from the population of ethnic villages such as Vanzetur, Shaitanka, Nizhnie Narykary, Ustrem, Tegi, Vanzevat, Aneevo, Lombovozh, Sosva, Sartynia located in Berezovskii District of the Khanty-Mansi Autonomous Okrug are used in this study (Fig. 1). A total of 395 individuals ( 9 men, 64 women, and 322 children) were examined. The inquired population was classified into adult (over 16 years) and children (5 to 15 years); and by ethnic 


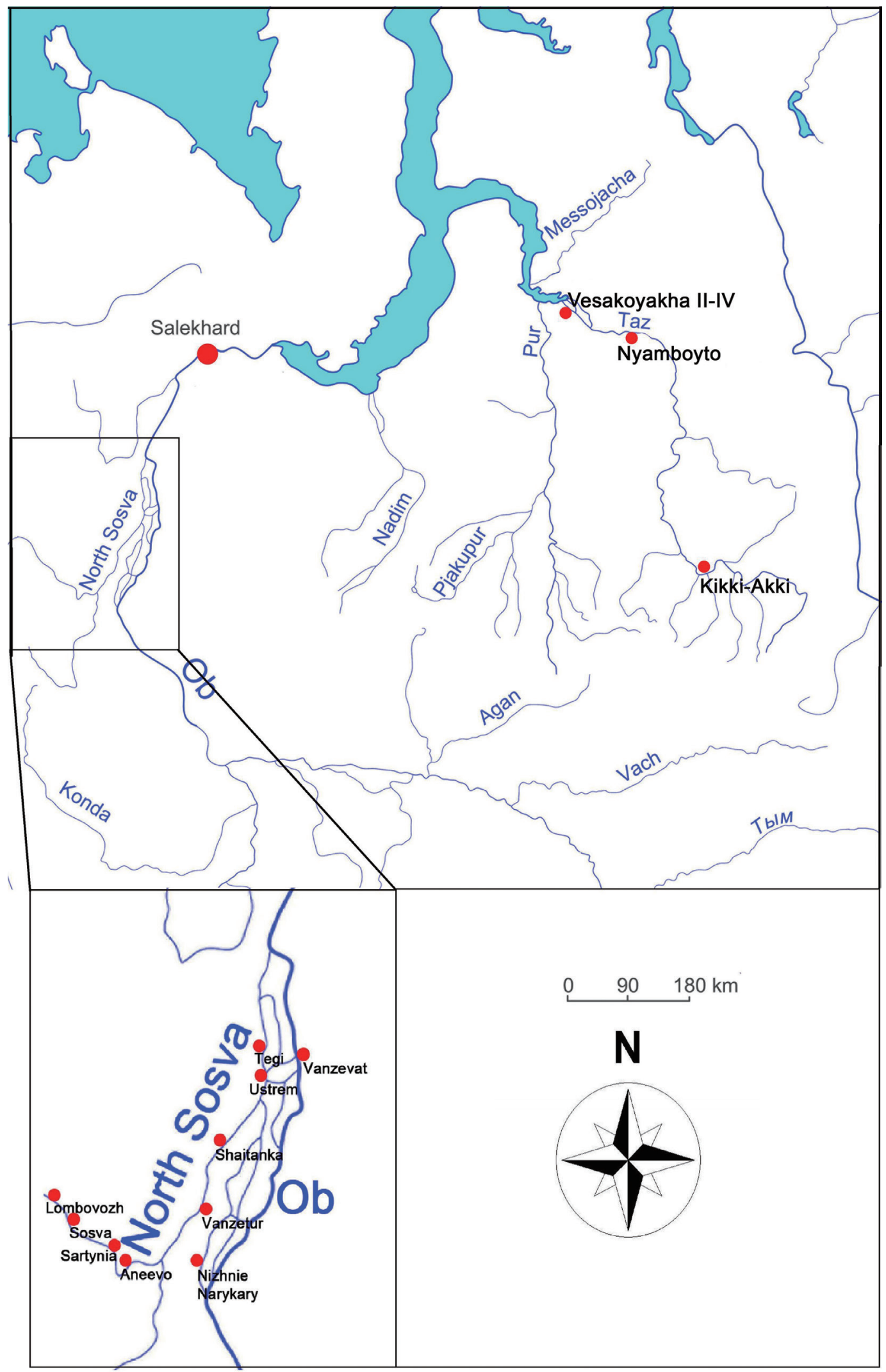

Fig. 1. Location of the West Siberian sites for which parasite examinations were performed. 
Table 1. Occurrence and confidence intervals of parasites detected during coproovoscopy on the modern populations of Western Siberia

\begin{tabular}{|c|c|c|c|c|c|c|c|}
\hline & \multirow{2}{*}{$\mathrm{N}$} & \multicolumn{2}{|c|}{ Opisthorchis felineus } & \multicolumn{2}{|c|}{ Ascaris lumbricoides } & \multicolumn{2}{|c|}{ Enterobius vermicularis } \\
\hline & & $n$ & Prevalence (95\%, conf) & $\mathrm{n}$ & Prevalence (95\%, conf) & $\mathrm{n}$ & Prevalence (95\%, conf) \\
\hline Khanty & 108 & 14 & $13.00(7.75-20.73)$ & 14 & $13.00(7.75-20.73)$ & 11 & $10.20(5.42-17.48)$ \\
\hline Male & 3 & 1 & $33.30(1.70-86.46)$ & 2 & 66.70 (13.54-98.30) & 0 & $0.00(0.00-63.15)$ \\
\hline Female & 32 & 12 & $37.50(21.75-55.37)$ & 8 & 25.00 (12.16-42.33) & 2 & $6.30(1.13-20.01)$ \\
\hline Children & 73 & 1 & $1.30(0.08-7.30)$ & 4 & $5.50(1.90-13.48)$ & 9 & $12.30(6.37-21.79)$ \\
\hline Mansi & 218 & 14 & $6.40(3.80-10.49)$ & 16 & $7.30(4.52-11.63)$ & 41 & $18.80(13.99-24.50)$ \\
\hline Male & 2 & 2 & $100.00(22.37-100.00)$ & 0 & $0.00(0.00-77.63)$ & 1 & $50.00(2.54-97.46)$ \\
\hline Female & 19 & 11 & $57.90(34.49-77.81)$ & 2 & $10.50(1.90-31.57)$ & 2 & $10.50(1.90-31.57)$ \\
\hline Children & 197 & 1 & $0.50(0.03-2.91)$ & 14 & $7.10(4.22-11.60)$ & 38 & $19.30(14.15-25.34)$ \\
\hline Russian old-timers & 69 & 6 & $8.70(3.86-17.93)$ & 2 & $2.90(0.52-9.93)$ & 15 & $21.70(13.36-33.23)$ \\
\hline Male & 4 & 1 & $25.00(1.28-75.13)$ & 0 & $0.00(0.00-52.71)$ & 0 & $0.00(0.00-52.71)$ \\
\hline Female & 13 & 3 & $23.00(6.61-51.96)$ & 0 & $0.00(0.00-22.51)$ & 0 & $0.00(0.00-22.51)$ \\
\hline Children & 52 & 2 & $3.8 .00(0.69-13.16)$ & 2 & $3.80(0.69-13.16)$ & 15 & $28.80(18.08-42.42)$ \\
\hline All & 395 & 33 & $8.40(5.90-11.48)$ & 32 & $8.10(5.72-11.23)$ & 57 & $14.40(11.24-18.32)$ \\
\hline
\end{tabular}

$\mathrm{N}$, the number of people surveyed; $\mathrm{n}$, the number of people affected by parasitosis.

groups, into Khanty (108), Mansi (218), and Russian old-timers (69 individuals). Of them, most Khanty and Mansi people still followed their traditional cultures and diet habits. Russian old-timers are the immigrants from Russia who have lived in Siberia for multiple generations. They eventually adopted the dietary habit of raw fish eating from Western Siberian natives. Fishing and hunting are the culture-economic basis of the indigenous peoples and Russian old-timers.

Copro-ovoscopic examination of Fulleborn technique [6] was used for the samples acquired from the residents of the above-mentioned settlements. The samples were processed in the laboratory by Callen \& Cameron technique [7]. Prevalence values ( $\mathrm{Pr}, \%)$ and their confidence intervals were calculated to estimate the relative abundance of parasites. Quantitative Parasitology 3.0 software [8] was used to calculate infection rates and to compare them.

In the late 20th century specimens, we observed the parasite eggs of 3 different species: Opisthochis felineus, Ascaris lumbricoides, and Enterobius vermicularis. The prevalence and confidence intervals of the parasites in the studied groups are presented in Table 1. Briefly, the opisthorchiasis infection rate was the highest in the Khanty (13\%), intermediate in Russian old-timers (8.4\%) and the lowest in the Mansi (6.4\%) though the differences in opisthorchiasis prevalence between the indigenous population and Russian old-timers were not statistically significant $\left(\chi^{2}=3.9, \mathrm{df}=2, P\right.$-value $\left.=0.140\right)$. Meanwhile, significant intergroup differences were identified in terms of opisthorchiasis infection rate between the adult samples of each group $\left(\chi^{2}=6.1 \mathrm{df}=2, P\right.$-value $\left.=0.046\right) ;$ and at this time, the order of infection rate was changed into $61.9 \%$ in Mansi, $37.1 \%$ in Khanty, and 23.5\% in Russian old-timers. This implies that there is still a difference in infection rate of opisthochiasis between them though Russian old-timers adopted the tradition of eating raw fish from indigenous peoples of Western Siberia.

Ascaris lumbricoides and Enterobius vermicularis eggs were found both in indigenous population and Russian old-timers. However, statistically significant difference between each population group was observed only in terms of ascariasis prevalence $\left(\chi^{2}=\right.$ $6.1, \mathrm{df}=2, P$-value $=0.047)$. The highest ascariasis infection rate was observed in Khanty (13\%), followed by Mansi (7.3\%), and Russian old-timers (2.9\%). In case of the enterobiasis prevalence, no statistically significant differences were found between the groups we examined $\left(\chi^{2}=5.2, \mathrm{df}=2, P\right.$-value $\left.=0.076\right)$ though Russian old-timers were the most highly infected group (21.7\%), intermediate for Mansi (18.8\%) and the lowest for Khanty (10.2\%) (Table 1).

Next, we also analyzed archaeoparasitological results obtained from our studies on Vesakoyakha, Kikki-Akki, and Nyamboyto I burial grounds in Western Siberia [5-10] (Fig. 1). Specimens of the 18th to the beginning of 20th centuries were obtained at 5 different burial grounds (at the territory of Tazovsky and Krasnoselkupsky districts) present in the Yamalo-Nenets Autonomous Okrug. Of them, (1) the 19th century Vesakoyakha II-IV burial grounds were created by the Nenets, nomadic reindeer herders on the Vesakoyakha River. A data of 14 individuals (7 men, 5 women, and 2 children) were reported from the place. (2) The Kikki-Akki burial ground, dated back to the 18th century, was created by the Taz Selkups, the hunters and 

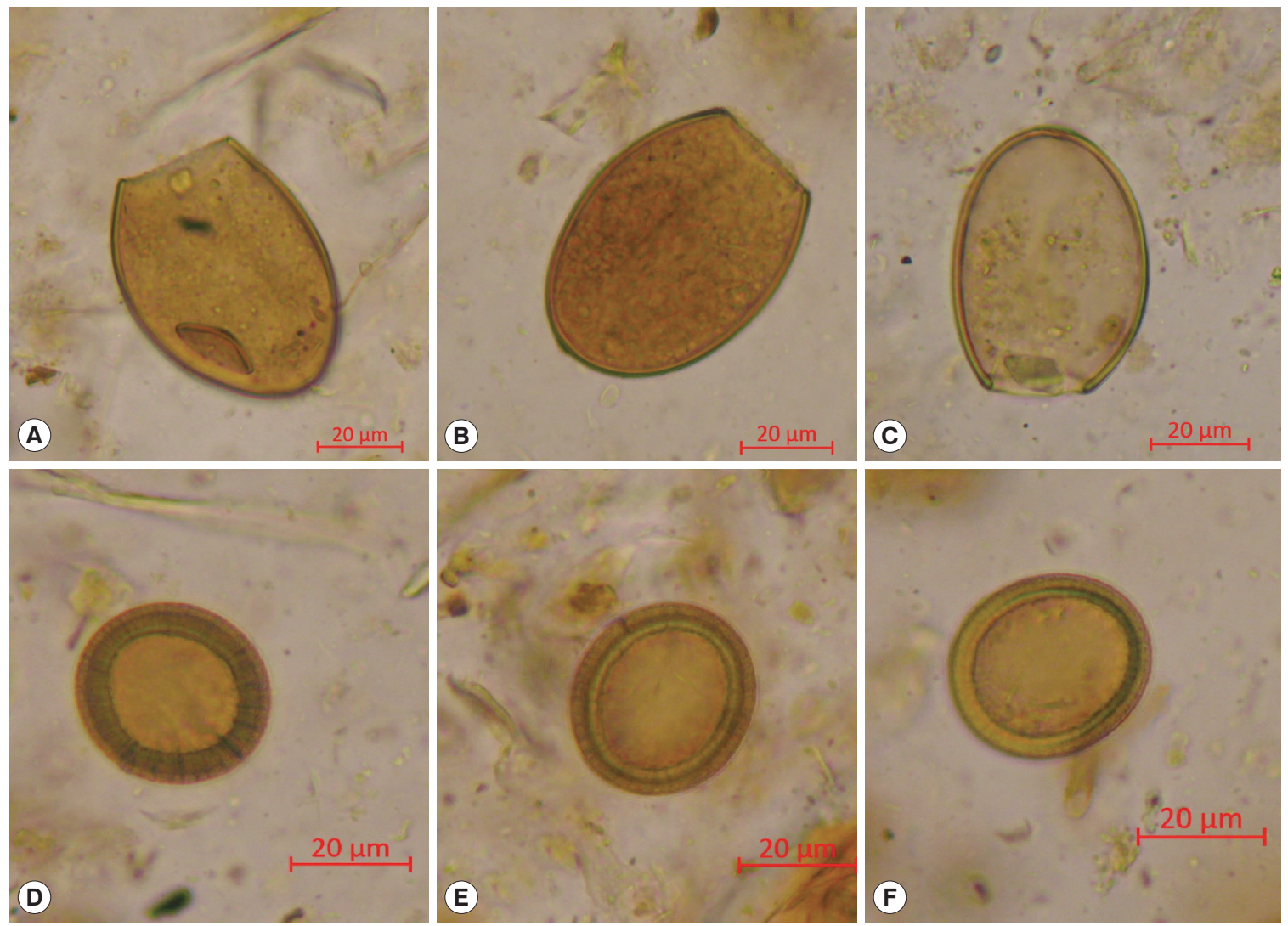

Fig. 2. Diphyllobothrium sp. eggs (A-C) and Taenia sp. eggs (D-F) found in the archaeological sites.

fishermen [11,12]. From the site, a total of 22 individuals were studied, comprising 11 men, 8 women, and 3 children. (3) The Nyamboyto I burial ground was formed in the first quarter of the 20th century, by the fishermen Nenets living along the shores of the Nyamboyto Lake [9]. 13 individuals were studied, of which 4 men, 1 woman, and 8 children were included.

In the archaeoparasitological study, the eggs of Diphyllobothrium and Taenia spp. were found in Vesakoyakha II-IV, Nyamboyto I and Kikki-Akki burial ground specimens (Fig. 2). However, no nematode (soil-transmitted) eggs were identified in the same soil samples. The prevalence and confidence intervals of parasites at the burial grounds of interest are presented in Table 2.

In case of Diphyllobothrium sp., they were found in all the archaeoparasitology groups (Vesakoyakha, Nyamboyto I and Kikki-Akki), for which intergroup differences were statistically significant $\left(\chi^{2}=9.5, \mathrm{df}=2, P\right.$-value $\left.=0.009\right)$. Among them, the Nyamboyto I sample demonstrated the highest infection rate (84.6\%) of Diphyllobothrium infection. This could be understandable because the buried individuals at the Nyamboyto I were the fishermen Nenets. The lowest rate was of Vesa-
Table 2. Occurrence and confidence intervals of parasites found in the populations of the 18th-early 20th centuries

\begin{tabular}{|c|c|c|c|c|c|}
\hline & \multicolumn{3}{|r|}{ Diphyllobothrium sp. } & \multicolumn{2}{|r|}{ Taenia sp. } \\
\hline & N & $n$ & $\begin{array}{l}\text { Prevalence } \\
\text { (95\%, conf) }\end{array}$ & $n$ & $\begin{array}{l}\text { Prevalence } \\
\text { (95\%, conf) }\end{array}$ \\
\hline $\begin{array}{l}\text { Vesakoyakha } \\
\text { II-IV }\end{array}$ & 14 & 4 & $26.80(10.40-57.40)$ & 2 & $15.40(2.80-43.40)$ \\
\hline Male & 7 & 3 & $41.90(12.90-72.10)$ & 2 & $28.60(5.30-65.90)$ \\
\hline Female & 5 & 1 & $20.00(1.00-65.70)$ & 0 & \\
\hline Children & 2 & 0 & & 0 & \\
\hline Nyamboyto I & 13 & 11 & $84.60(56.60-97.20)$ & 0 & \\
\hline Male & 4 & 4 & $100.00(47.30-100.00)$ & 0 & \\
\hline Female & 1 & & $100.00(50.00-100.00)$ & 0 & \\
\hline Children & 8 & 6 & 75.00 (36.50-95.40) & 0 & \\
\hline Kikki-Akki & 22 & 9 & $40.90(20.70-63.60)$ & 0 & \\
\hline Male & 11 & 6 & $44.50(26.50-80.00)$ & 0 & \\
\hline Female & 8 & 1 & $12.50(0.64-50.00)$ & 0 & \\
\hline Children & 3 & 2 & $66.70(13.50-98.30)$ & 0 & \\
\hline All & 62 & 26 & $41.90(29.70-54.90)$ & 2 & $3.20(0.60-11.00)$ \\
\hline
\end{tabular}

$\mathrm{N}$, the number of people surveyed; $\mathrm{n}$, the number of people affected by parasitosis. 
koyakha II-IV (26.8\%), the burial site for Nenets reindeer herders who depended on meats for their diets. The difference of these 2 groups (Nyamboyto I and Vesakoyakha) was statistically significant $(P$-value $=0.006)$ (Table 2$)$. Obviously, higher diphyllobothriasis rate must have been related with a fisherybased, sedentary life in history whereas lower rate of diphyllobothriasis represents a nomadic lifestyle of reindeer herders whose diets were mainly composed of meats.

We also note that Taenia sp. eggs were found only in the specimens from the Vesakoyakha II-IV sites (prevalence, $15.4 \%$ ). Since the burial grounds were made and maintained by Nenets the reindeer herders, we speculate that Taenia sp. Infection among them might have induced by the ingestion of raw reindeer brain $[9,13]$. Our speculation could be supported by Guzeeva's epidemiological study that $99.15 \pm 0.9 \%$ of Taenia infection among Nenets people were caused by the ingestion of reindeer brain while a minimal cysticercosis infection rate was observed among the Komi reindeer herders who don't have the tradition of eating raw reindeer brain [13].

In this study, by considering both contemporary and archaeoparasitological data together, we manage to reveal novel knowledge concerning the parasite infection pattern in arctic and subarctic areas of Western Siberia. First, the results of archaeoparasitological analysis of the Kikki-Akki, Vesakoyakha II-IV, and Nyamboyto I burial ground samples demonstrated that the parasite eggs found in them was mainly associated with Diphyllobothrium sp $[9,10]$. Our study on the late 20th century populations also revealed that Khanty, Mansi and Russian old-timers were affected by opisthorchiasis. Since both Diphyllobothrium and Opisthochis infections are caused by ingestion of raw and/or insufficiently cooked fishes, the raw fisheating tradition seems not to have undergone radical changes since the 18th century.

Next, we found statistically valid difference in Opisthochis infection between the adults (41.1\%) and children (1.2\%) of the contemporary people (Khanty, Mansi and Russian old-timers) (the difference is significant $P$-value $\leq 0.001$ ). For this, we presume that children did not eat adult foods containing raw or undercooked fishes; or regular treatment of parasiticide for children at school might have been successful at the time. However, unlike contemporary groups, no differences were found between the children and adults in archaeoparastiological specimens $(P$-value $=0.206)$. We conclude that children in West Siberian populations in the 18th to the early 20th century might have been provided with the adult foods, which could be also supported by previous ethnographic and archaeoparasitological reports [5,14-18].

Finally, we note that A. lumbricoides or E. vermicularis eggs were not found in the archaeoparasitological specimens (Vesakoyakha, Kikki-Akki, and Nyamboyto I). The absence of the eggs might be explained by the arctic soils' poorly preserved condition in Siberia. The absence of $E$. vermicularis eggs in archaeological samples could be also explained by the fragile features of their eggs. However, this explanation could not be easily accepted because the authors observed very well-preserved parasite eggs in the other arctic or subarctic specimens of Siberia $[9,10]$. Instead, it might be true that A. lumbricoides or $E$. vermicularis did not infect the inhabitants of this area at that time. In this regard, finding those parasite eggs in the contemporary samples (Khanty, Mansi, and Russian old-timers) might have been caused by the indigenous people's change in the way of life during the Soviet Union period. Rapid spread of the helminth infection could be induced by an increase in person-to-person contacts because the Siberian people can live together with the Russian immigrants in over-crowded places.

With respect to parasite infections in the arctic and subarctic areas of Western Siberia, we caught a glimpse of the parasite infection pattern prevalent therein via investigations on contemporary and archaeoparasitological specimens. In this study, the spatio-temporal pattern of parasite infection could be revealed by the analyses of different samples representative of the 18th to 20th century human populations in the same region. The changes in dietary habits and life style during the 20th century seem to have influenced on parasite infection among Siberian indigenous peoples. Plausible causes of the change in parasitism in Siberian arctic and subarctic areas could also be presumed in this report.

\section{ACKNOWLEDGMENTS}

The part of the present work was funded by State Task (program XII.186.4, project No. AAAA-A17-117050400143-4 of Tyumen Scientific Center SB RAS). Investigations of S.V. Bugmyrin were carried out under state order for IB KarRC RAS (0218-2019-0075). Partly supported by Russian Foundation for Basic Research grants 17-06-00302-A (S.M.S.) and 18-0900487 (A.I.K. and G.G.V.). This research was also supported by Basic Science Research Program through the National Research Foundation of Korea (NRF) funded by the Ministry of Education (2017R1D1A1B03030127). 


\section{CONFLICT OF INTEREST}

The authors declare no conflict of interest related to this study.

\section{REFERENCES}

1. Sianto L, Chame M, Silva CSP, Gonçalves ML, Reinhard K, Fugassa $\mathrm{M}$, Araújo A. Animal helminths in human archaeological remains: A review of zoonoses in the past. Rev Inst Med Trop Sao Paulo 2009; 51: 119-130.

2. Dutour O. Paleoparasitology and paleopathology. Synergies for reconstructing the past of human infectious diseases and their pathocenosis. Int J Paleopathol 2013; 3: 145-149.

3. Araújo A, Reinhard K, LF Ferreira. Parasite findings in archeological remains: Diagnosis and interpretation. Quat Int 2008; 180 : 17-21.

4. Araújo A, Reinhard KJ, Ferreira LF, Gardner SL. Parasites as probes for prehistoric human migrations? Trends Parasitol 2008; 24: 112115.

5. Slepchenko S, Reinhard K. Paleoparasitology and pathoecology in Russia: investigations and perspectives. Int J Paleopathol 2018; 22: $39-44$.

6. Fulleborn F. Die Anreicherungen der Helmintheneier mit Kochsalzlösung. Dtsch Med Wochenschr 1920; 46: 714-715 (in Dutch).

7. Callen EO, Cameron TWM. A prehistoric diet revealed in coprolites. New Scientist 1960; 8: 35-40.

8. Reiczigel J, Rózsa L. Quantitative Parasitology 3.0 [Internet]; Budapest, Hungary. 2005. Available from: http://www.zoologia.hu/ qp/qp.html.

9. Slepchenko SM, Ivanov SN, Nikolaevich BA, Alekseevich TA, Ser- geyevich SV. Traditional living habits of the taz tundra population: A paleoparasitological study. Korean J Parasitol 2016; 54: 617-623.

10. Slepchenko SM, Ivanov SN. Paleoparasitological analysis of soil samples from the Kikki-Akki burial ground of the 17th-19th centuries in West Siberia, Russia. J Archaeol Sci Rep 2015; 2: 467-472.

11. Poshekhonova OE, Kisagulov AV, Gimranov DO, Nekrasov AE, Afonin AS. Transformation of Upper Taz Selkup funeral rites according to paleoecological data. J Archaeol Sci Rep 2018; 22: 132141.

12. Kvashnin YN, Tkachev AA. Cult place on the lake Nyamboyto. Anthropol forum 2014; 23: 185-194.

13. Guzeeva TM. Optimization of Epidemiological Surveillance of Biohelminthoses (Doctoral dissertation). Moscow, Russian Federation. Science. 2011, pp 295.

14. Slepchenko SM, Ivanov SN, Gusev AV, Svyatova EO, Fedorova $\mathrm{NV}$. Archaeoparasitological and palynological analysis of samples from the intestinal contents of a child mummy from the Zeleniy Yar burial ground (12-13th centuries AD). Archaeol Res Asia 2019; 17: 133-136.

15. Slepchenko S, Kardash O, Ivanov S, Afonin A, Shin DH, Hong JH. The Buchta-Nakhodka 2 burial ground: Results of archaeoparasitological and macro-remains investigations of samples from the burial grounds of the 6th-13th century CE on the Yamal Peninsula in Russia. J Archaeol Sci Rep 2019; 23: 791-799.

16. Khomich LV. Nenets. Moscow, Russian Federation. Science. 1966, pp 329.

17. Zuev VF. Materials on the Ethnography of the XVIII Century (17711772). Moscow, Russian Federation. Academy of Sciences. 1947, pp 96.

18. Miller GF. The History of Siberia. Vol. 2. Moscow, Russian Federation. Eastern Literature. 2000, pp 796. 